\title{
The role of fluoride tablets in the prophylaxis of dental caries. A literature review
}

\author{
Lisa Tomasin, DDS \\ Luca Pusinanti, DDS \\ Nicoletta Zerman, MD, SDS
}

Department of Pediatric Dentistry, Dental School, University of Verona, Italy

\section{Corresponding author:}

Lisa Tomasin

Department of Pediatric Dentistry, Dental School, University of Verona, Policlinico G.B. Rossi

P.le L.A. Scuro, 10

37134 Verona, Italy

E-mail: nicoletta.zerman@univr.it

\section{Summary}

Aim. Doing a meta-analysis to answer the question: "Does fluoride tablets prevent dental caries among children and adolescents?"

Materials and methods. A review of the literature is performed using the following databases: PubMed, Embase, CINAHL, Cochrane Library, Embase, NHS Evidence Oral Health, PsycINFO, Web of Knowledge, Metalib. The keywords used are dental fluoride, fluoride tablets. The studies analyzed was limited to English language with free abstract. For the studies selection was taken into consideration the criteria proposed by the Cochrane Oral Health Group.

Results. Few studies with good quality were identified in general. Only 3 out of 779 studies were acceptable.

Conclusions. Evident disagreements among the results show that there's a limited effectiveness on fluoride tablets.

Key words: fluoride tablets, dental fluoride.

\section{Introduction}

The prophylaxis with fluoride tablets represents an interesting topic for dentists because there are questions still remain open.

In view of recommendations and national and international guidelines that clear the doubts on the issue, the practical problem consists in understanding how useful it is to suggest the use of fluoride supplements to patients, in which quantity and time-frame, or if it is better to replace this practice with other prevention methods.

A literature review was done to answer the question: Do fluoride tablets prevent dental caries among children and adolescents?

\section{Materials and methods}

A review of the existing literature edited in English has been performed using the following databases: PubMed, CINAHL, Cochrane Library, Embase, NHS Evidence Oral Health, PsycINFO, Web of Knowledge, Metalib. The keywords used have been: dental fluoride, fluoride tablets.

The objective is to evaluate the effects of the ingestion of fluoride supplements in the form of tablets (chewable or not) for preventing dental caries in children.

Do fluoride tablets prevent dental caries among children and adolescents?

The studies selection process has been conducted according to the Cochrane Oral Health Group criteria described in detail by Tubert-Jeannin et al. in 2009 (1); according to these criteria only randomized controlled clinical trials (RCTs) with randomization at the level of the child or at the level of a group have been analyzed.

Other study designs as non-randomized controlled clinical trials, prospective cohort studies, historical control studies and retrospective epidemiological studies have been excluded. Studies with an intervention or follow-up period of less than 2 years have been excluded as well. Studies where the active intervention consisted of any other systemically delivered fluoride (water, milk, salt) provided in addition to fluoride supplements have been excluded.

Studies in which a topical fluoride based measure or a non-fluoride based preventive measure applied in a control group was different from the one administered in the intervention group (in addition to fluoride supplements) have been excluded.

Surveys reporting only on changes in plaque, fluoride uptake by enamel or dentin or fluoride salivary secretion have been excluded.

Children or adolescents aged 16 or less at the start of the study have been included (irrespective of initial level of dental caries, background exposure to fluorides, dental treatment level, nationality, setting where intervention is received or time when it started). Older participants have been excluded to avoid the selection of studies concerning the use of fluoride supplements to prevent root caries or to improve bone density. 


\section{Tomasin et al.}

\section{Types of interventions}

Ingestion of fluoride tablets, with or without the use of vitamins, at any concentration, amount, frequency of use, duration of application, and with any technique of application (sucked or not, chewed or not, diluted or not before being swallowed, with or without the use of topical fluoride based measures) has been evaluated.

The control group has to be formed by children who have not taken fluoride supplement or have ingested a placebo supplement (with or without the use of vitamins), subjected to topical fluoride based measures as topical fluoride application, fluoride varnish or fluoride tooth paste or not undergone topical fluoride based measures but who have undergone non-fluoride based measure (chlorexidine, xylitol, sealants, oral hygiene interventions, etc.).

\section{Assessment parameters}

For permanent and deciduous dentition, changes in caries increment, as measured by the difference between the number of decayed, missing and filled teeth (dmft/DMFT) or surfaces (dmfs/DMFS) at baseline and at the time of final evaluation for the same children.

DMFT (Decayed, Missing, Filled Teeth) is determined by calculating the number of decayed, reconstructed or extracted permanent elements in a patient compared with the total number of present teeth (generally 28 in the permanent dentition, excluding the third molars). The dmft refers to the deciduous dentition. The DMFS/dmfs considers the teeth surfaces as well. The difference in the caries incidence in permanent and deciduous dentition is measured this way in the treatment and control groups (if the groups are comparable at baseline).

The method of assessment executed has been recorded (clinical and radiographic).

Adverse effects will be recorded and noted.
Dental fluorosis has to be assessed with a specific index and any other possible negative effects has to be sought.

For each RCT the following data will be recorded:

- Author(s), year of publication, number of reports on the study, country.

- Methods: study design, research objective, study duration, randomization, unit (individual/cluster), comparability of baseline characteristics, blindness of participants, blindness in outcome assessment, reliability of primary outcome measurement, co-intervention and/or contamination, institutions and manufacturers involved, local characteristics.

- Participants: setting where participants were recruited, criteria for inclusion, demographic characteristics (age, gender, socio-economical status), caries severity, exposure to fluoride, number at start and at the end of the study.

- Intervention: tablets, treatment duration and application frequency, fluoride doses, combination of methods, compliance (supervision of participants).

- Details of the outcomes: method of assessment (clinical/radiographic), mean duration of study.

- Measures: units measured (tooth/surface), index used (DMFT/S), types of tooth/surface considered (deciduous, permanent).

- Adverse effects - fluorosis - is recorded.

\section{Results}

Many studies were identified, among which 3 have been judged usable and these have subsequently been analyzed in detail (Tab. 1).

\section{Discussion}

According to Limeback and other Authors weak scientific evidence support the effectiveness of fluoride supplements (2-5).

Table 1. Studies considered for the review.

\begin{tabular}{|c|c|c|c|c|c|}
\hline Author & $\begin{array}{l}\text { Study } \\
\text { type }\end{array}$ & $\begin{array}{l}\text { Patient } \\
\text { characteristics }\end{array}$ & Intervention/control group & Results (>DMFS) & Side effects \\
\hline $\begin{array}{l}\text { Driscoll WS, } \\
\text { Heifetz SB, } \\
\text { Brunelle JA. } \\
1979 \\
\text { USA }\end{array}$ & $\begin{array}{l}\mathrm{RCT} \\
\mathrm{DB}\end{array}$ & $\begin{array}{l}\text { Mean age } \\
6.6 \mathrm{yr} .\end{array}$ & $\begin{array}{l}\text { APF (acidulated } \\
\text { phosphate-fluoride) } \\
\text { tablet daily dosage } 1 \mathrm{mg} \mathrm{F} \text {. } \\
\text { Daily dosage APF } 2 \mathrm{mg} \mathrm{F} \text {. } \\
\text { Placebo tablets. }\end{array}$ & $\begin{array}{l}7.70 \\
\\
7.64 \\
11.53\end{array}$ & Not investigated \\
\hline $\begin{array}{l}\text { Lin YT, } \\
\text { Tsai CL. } \\
2000 \\
\text { Taiwan }\end{array}$ & $\mathrm{RCT}$ & $\begin{array}{l}\text { 22-26-month-old } \\
\text { children with } \\
\text { cleft lip and/or } \\
\text { palate. }\end{array}$ & $\begin{array}{l}\text { Daily } \mathrm{NaF} \text { tablet } 0.25 \mathrm{mg} \mathrm{F} \text {. } \\
\text { No fluoride supplement. }\end{array}$ & $\begin{array}{l}4.10 \\
8.35\end{array}$ & Not investigated \\
\hline $\begin{array}{l}\text { Stecksén-Blicks C, } \\
\text { Holgerson PL, } \\
\text { Twetman S. } \\
2008 \\
\text { Sweden }\end{array}$ & $\mathrm{RCT}$ & $\begin{array}{l}\text { 10-12-year-old } \\
\text { children with } \\
\text { hight caries risk. }\end{array}$ & $\begin{array}{l}\text { Daily dose } 2.5 \mathrm{~g} \text { xylitol in } \\
2 \text { tablets } x 3 \text { times daily. } \\
\text { Xylitol as above but tablets } \\
\text { did also contain } 0.25 \mathrm{mg} \mathrm{F} \text {. }\end{array}$ & 2.7 & Not investigated \\
\hline
\end{tabular}


The American Center for Disease Control (CDC) also has published in 2001 recommendations for using fluoride to prevent and control dental caries. They concluded that the quality of evidence to support use of fluoride supplements by children aged less than 6 years was low (6).

The Swedish Council on Technology Assessment in Health Care has also conducted a systematic review on the effectiveness of different measures for caries prevention. Five studies related to the effect of fluoride supplements on permanent teeth were included in this review. The authors concluded that there was no clear evidence that the use of fluoride supplements prevents dental caries on permanent teeth. They noticed that the only study that found a significant preventive effect of fluoride supplements was an old study conducted during the 70s (7).

Hasson et al., in 2008, examined evidence regarding the effectiveness of fluoride supplements in preventing caries and their association with dental fluorosis. They concluded that "there is weak and inconsistent evidence that the use of fluoride supplements prevents dental caries in primary teeth. There is evidence that such supplements prevent caries in permanent teeth. Mild-to-moderate dental fluorosis is a significant side effect" (8).

In 2009 Espelid conducted a systematic review on the efficacy of fluoride tablets in dental caries prevention. He found 7 satisfying studies according to the considered criteria. This happened because, unlike in this study, he modified the criteria described by Cochrane review (9).

However the Author resolved that "very few studies of good quality were identified in general" and that "there is limited evidence that F tablets are effective" hoping that there will be new, well-designed studies within this field in the future.

Espelid classifies the studies we explored with a 1level of evidence, meaning RCTs with a high risk of bias. On the contrary, among the ones he identified only 2 are worth a $1+$ level, being RCTs with a low risk of bias. However, in his opinion, these studies are very old.

The most recent review of the existing literature was done by Tubert-Jeannin for the Cochrane Oral Health Group at the end of 2011. In their review the Authors took into account fluoride supplements in general (tablets, drops, lozenges and chewing gums). Only 11 out of the 7196 studies were considered acceptable. The results of this review suggest that the use of fluoride supplements was associated with a reduction in DMFS between 95 and 16\% in permanent teeth. The effect of fluoride supplements was unclear on primary teeth. In one study, no caries-inhibiting effect was observed on deciduous teeth while, in another study, the use of fluoride supplements was associated with a substantial reduction in caries increment. The Authors rated " 10 trials as being at unclear risk of bias and 1 at high risk of bias, and therefore the trials provide weak evidence about the efficacy of fluoride supplements". Moreover the review found "limit- ed information on the adverse effects associated with the use of fluoride supplements" (10).

Driscoll's study of 1979 was conducted with children's supervised intervention in school; tablets were not given in weekends, holidays, or vacations (max 145 days with tablets per year). No radiographs were used in the evaluation and to an objective analysis it seems that tablets are most effective in approximal surfaces. The study was conducted in North Carolina, where the water fluoridation rate is lower than $0,03 \mathrm{ppm}$.

The Author concludes recommending the use of fluoride tablets in schools in areas where there is no water fluoridation (11).

In Lin's study (12) 59 males and 56 females (22-26month-old children with cleft lip and/or palate) were selected. The study was conducted in Taiwan, where there is no water fluoridation. The test group was administered with $0.25 \mathrm{mg}$ of fluoride a day. After two years, the DMFS analysis results stated that children taking F-tablets showed a borderline difference, not statistically relevant compared to the control group ( $p$ $=0,065$ ).

Children suffering from cleft lip and palate are, according to Lin, considered individuals with a high-risk of developing dental caries. As a matter of fact they have a high prevalence of $S$. Mutans from the age of 18 months. In the Author's opinion it is important to establish an early dental health program and to adequately inform parents in order to prevent potential future problems.

In Stecksèn-Blicks's study, 160 children aged 10-12 years with high caries risk were selected and randomly divided into two groups. The test group was administered with xylitol $(2.5 \mathrm{~g})$ and fluoride $(1.5 \mathrm{~g})$ in two tablets three times a day, while the control group was administered only with xylitol $(2.5 \mathrm{~g})$. Clinical assessment was followed by radiographic assessment. The compliance analysis showed that $29 \%$ of subjects rated as having poor compliance, $30 \%$ good compliance and $41 \%$ excellent compliance.

The study results show that "no statistical significant difference in dental caries incidence can be found between the two study groups ( $p>0.05$ )". The population of this study developed an average DMFS of 2.7 during this 2-year study, among which the majority (1.8) were lesions to approximal surfaces.

The Author concludes that "the results of this 2 years study do not support the administration of tablets containing fluoride and xylitol for dental caries prevention among young adolescents with a high caries risk" (13). Burt stated as well that "little firm evidence exists for the efficacy of dietary fluoride supplements when taken from birth or soon after" adding that "fluoride supplements are a risk factor for fluorosis" and that "the preeruptive cariostatic benefits of fluoride are minor" (14). According to the Author, "fluoride supplements, when ingested for a pre-eruptive effect by infants and young children, therefore carry more risk than benefit".

In the existing literature there are actually very few exceptions against the use of fluoride tablets, the majority support the administration of these supplements 
proving the benefits derived from consumption. According to Burt, design faults are common in these studies. Some of these problems, for example, can be found in a 1978 review where Burt noticed that the studies took into account selected participants without randomization and that there was no control group. According to this review prophylaxis with fluoride tablets entails a caries reduction fluctuating between 50 and $80 \%$ in the primary dentition and between 20 and $40 \%$ in the permanent dentition (15).

Burt mentions other studies in which the design faults are so serious that they can call the results validity into question. For example, in a retrospective study, Aasenden and Peebles (16) maintain an $80 \%$ reduction in caries prevalence among children who were administered with fluoride supplements from birth, compared with children who didn't take any. However in this study there was a serious mistake; children belonging to the group administered with fluoride were not randomly chosen. Burt noticed that children belonging to this group turned out to have a decidedly better oral hygiene compared to the ones who were not taking any tablets and they were mainly females. This fact, according to the author, is the reason of results alteration (14).

According to Riordan it is difficult to conduct ethical and adequate studies on fluoride supplements and on dental caries prevention (17). Studies should include a very high number of participants, given the continuous decrease of dental caries prevalence; this raises considerably the cost of the study (18). Moreover the testing should last long enough to allow caries to appear, but this doesn't happen often because of the population's mobility and because of many parents reluctance to comply with the dosage schedule for an extended period of time. Furthermore, some individuals could leave the study in long time scales. Riordan maintains that all these variables can alter the testing results (17).

Only a few supplement studies have taken account of factors such as socio-economic status or parent's educational level, but these studies suggest that such variables are more important for caries prevention than the use of supplements (19-21).

According to Spencer "fluoride can prevent caries up to $71 \%$ " but just $2 \%$ of this reduction is due to the contribution of tablets and the reasons for the low contribution of fluoride supplements were poor efficacy in a time when caries incidence is low, and poor compliance with recommendations to use it (22).

Therefore the statement of any preventive procedure should occur, as much as possible, according to the existence of clinical studies that meet given quality criteria.

From this studies one can infer that while some preventive benefits are possible, especially with regard to topical action, the evidence of efficacy of fluoride tablets used from birth or from childhood is not strong enough. Comparing risks and benefits the balance is against the use of this methodology because, as said before, fluoride has little effect on caries prevention but involves an evident risk for dental fluorosis. For this reason, according to Burt, "fluoride supplements should no longer be used for young children" (14). In conclusion, only 3 studies met the inclusion criteria and they show contrasting results: Driscoll supports the efficacy of fluoride tablets to prevent caries, Lin maintains that children in the test group presented a borderline, but non-significant statistical difference when compared with the control group, while Stecksén-Blicks doesn't find any reason for the utilization. Differences between the different study designs don't help the comparison. For the same reason it is not easy to increase the examined sample aggregating different studies.

F-doses as well are dissenting, this being an important start point for the evaluation of effects, given that it is well known that the effect on caries prophylaxis is dose dependent.

Therefore, there is a limited evidence about fluoride tablets efficacy.

There is a need for new, well-designed studies within this field, taking into account possible negative effects as well, allowing a better search of advantages and disadvantages of this prophylaxis method.

Despite the fact that results discourage a systemic and prenatal administration, this is still in use, showing low professional updating.

\section{References}

1. Tubert-Jeannin S, Tramini P, Gerbaud L, Amsallem E, Schulte A, Auclair C, Ismail A. Fluoride supplements (tablets, drops, lozenges or chewing gums) for preventing dental caries in children. Editorial Group: Cochrane Oral Health Group. Published Online: 21 JAN 2009.

2. Limeback $H$, Ismail $A$, Banting $D$, DenBesten $P$, Featherstone J, Riordan PJ. Canadian Consensus Conference on the appropriate use of fluoride supplements for the prevention of dental caries in children. J Can Dent Assoc. 1998 Oct;64(9):636-9.

3. Clark DC. Appropriate uses of fluorides for children: guidelines from the Canadian Workshop on the Evaluation of Current Recommendations Concerning Fluorides. J Can Med Assoc. 1993;149:1787-93.

4. Ismail A. Fluoride supplements: current effectiveness, side effects and recommendations. Community Dent Oral Epidemiol. 1994;22:164-72.

5. Nojwack-Raymer R, Driscoll WS, Selwitz R, Li S-H, Heifetz $\mathrm{SB}$. A comparison of the caries preventive effects of fluoride mouth rinsing, fluoride tablets and both procedures combined: final results after eight years. J Public Health Dent. 1992;52;111-6.

6. Centers for Disease Control and Prevention. Recommendations for using fluoride to prevent and control dental caries in the United States. Morbidity and Mortality Weekly Report: Recommendation Report. 2001;50(RR-14):1-42.

7. The Swedish Council on technology assessment in health care. Prevention of dental caries. A systematic review. 2002; Vol. report n.161.

8. Hasson $\mathrm{H}$, Ismail A. Fluoride supplements, dental caries and fluorosis: a systematic review. J Am Dent Assoc. 2008; 139(11):1457-68.

9. Espelid I. Caries preventive effect of fluoride in milk, salt and tablets: a literature review. Eur Arch Paediatr Dent. 2009;10(3):149-56. 
10. Tubert-Jeannin S, Auclair C, Amsallem E, Tramini P, Gerbaud L, Ruffieux C, Schulte AG, Koch MJ, Rège-Walther M, Ismail A. Fluoride supplements (tablets, drops, lozenges or chewing gums) for preventing dental caries in children (Review). The Cochrane Library. 2011, Issue 12.

11. Driscoll WS, Heifetz SB, Brunnelle JA. Treatment and post-treatment effects of chewable fluoride tablets on dental caries: findings after $71 / 2$ years. J Am Dent Assoc. 1979;99(5):817-21.

12. Lin YT, Tsai CL. Comparative anti-caries effects of tablet and liquid fluorides in cleft children. J Clin Dent. 2000;11(4):104-6.

13. Stecksén-Blicks C, Holgerson PL, Twetman S. Effect of xylitol and xylitol-fluoride elozenges on approximal caries development in high-caries-risk children. Int J Paediatr Dent. 2008;18(3):170-7.

14. Burt BA. The case for eliminating the use of dietary fluoride supplements for young children. J Public Health Dent. 1999 Fall;59(4):269-74.

15. Binder K, Driscoll WS, Schutzmannsky G. Caries-preventive fluoride tablet programs. Caries Res. 1978;12:22-30.

16. Aasenden R, Peebles TC. Effects of fluoride supplementa- tion from birth on deciduous and permanent teeth. Arch Ora Biol. 1974;19:321-6.

17. Riordan PJ. The place of fluoride supplements in caries prevention today. Aust Dent J. 1996;41(5):335-42.

18. O'Rourke CA, Attrill M, Holloway PJ. Cost appraisal of a fluoride tablet program to Manchester primary schoolchildren. Community Dent Oral Epidemiol. 1988;16(6):341-4.

19. Friis-Hasche E, Bergmann J, Wenzel A, et al. Dental health status and attitudes to dental care in families participating in a Danish fluoride tablet program. Community Dent Oral Epidemiol. 1984;12:303-7.

20. Kalsbeek H, Verrips GH, Backer Dirks O. Use of fluoride tablets and effect on prevalence of dental caries and dental fluorosis. Community Dent Oral Epidemiol. 1992;20:241-5.

21. Tijmstra T, Brinkman-Engels M, Groeneveld A. Effect of socioeconomic factors on the observed caries reduction after fluoride tablet and fluoride toothpaste consumption. Community Dent Oral Epidemiol. 1978;6:227-30.

22. Spencer AJ. Contribution of fluoride vehicles to change in caries severity in Australian adolescents. Community Dent Oral Epidemiol. 1986;14:238-41. 